\title{
Comparative analysis of fetomaternal outcome in women with gestational diabetes mellitus managed on different modalities
}

\author{
Sumedha Gupta, Upma Saxena, Renu Arora, Vijay Zutshi, Ritu Aggarwal \\ Corresponding author: Dr. Upma Saxena, Professor, MD, FICOG, FICMCH, Dept of OBGYN, VMMC \& \\ Safdarjung Hospital, New Delhi, India; Email : upma_saxena@hotmail.com
}

Distributed under Attribution-Non Commercial - Share Alike 4.0 International (CC BY-NC-SA 4.0)

\begin{abstract}
Objectives: To compare fetomaternal outcome in women of gestational diabetes mellitus (GDM) managed on different modalities. Methods: A retrospective observational study was conducted in department of obstetrics and gynaecology at Vardhman Mahavir Medical College and Safdarjung Hospital, New Delhi. All case records of 352 women with singleton pregnancy diagnosed with GDM in the hospital managed on different modalities, over a period of 18 month, were reviewed. Diagnosis of GDM was made according to guidelines of diabetes in pregnancy study group of India (DIPSI). They were divided into four groups, group A - MNT (medical nutrition therapy) (140 patients), group B - MNT plus metformin (90 patients), group C - MNT plus insulin (90 patients), group D - MNT plus metformin plus insulin (32 patients). Fetomaternal outcomes of GDM women managed on different modalities were recorded. Results: All the 4 groups of the patient in this study were demographically matched. There was no statistically significant difference in total weight gain during pregnancy $(p=0.6012)$, mode of delivery $(p=0.420)$, preterm delivery $(p=0.059)$, urinary tract infection $(p=0.387)$, hypertensive disorder in pregnancy $(p=0.773)$, and postpartum haemorrhage $(\mathrm{p}=0.2656)$ between insulin $\mathrm{v} / \mathrm{s}$ metformin group and MNT v/s metformin group. But incidence of polyhydramnios was significantly $(\mathrm{p}=0.0230)$ higher in metformin group than in MNT group. Conclusion: Our study concluded that metformin seems to be an effective oral hypoglycemic drug in the treatment of GDM and does not appears to be associated with increased maternal and neonatal complications compared to insulin.
\end{abstract}

Keywords: Gestational diabetes mellitus, medical nutrition therapy, metformin, insulin, fetomaternal

outcome.

The incidence of gestational diabetes mellitus (GDM) is increasing worldwide with prevalence of $1-14 \%{ }^{1,2}$ GDM is associated with higher fetomaternal risks as it increases the occurrence of preeclampsia, caesarean delivery and type 2 diabetes later on, in the mother. ${ }^{3}$ Whenever a women is diagnosed with GDM, she receives advice regarding medical nutrition therapy (MNT) and lifestyle modification. Pharmacological therapy is initiated only when target blood glucose levels are not attained with these modifications. ${ }^{4}$ Proper control of blood sugars in GDM, has been shown to significantly improve perinatal outcomes, with decreased occurrence of macrosomia, birth injury and neonatal death. ${ }^{5}$
A large number of previous studies have concluded that treatment of GDM with metformin leads to adequate glycemic control without increasing the risk of adverse perinatal outcomes. ${ }^{6,7}$ Metformin acts by suppressing hepatic gluconeogenesis and by increasing insulin sensitivity, leading to control of hyperglycaemia.

Metformin may be a more favourable alternative to insulin, as it does not increase maternal weight and is also not associated with hypoglycaemia, with additional advantages of avoiding need for injections and also makes maternal follow-up much simpler. ${ }^{8}$ Use of metformin from 12 to 18 weeks of gestation, reduces gestational weight gain

Received: $6^{\text {th }}$ February 2021, Peer review completed: $24^{\text {th }}$ March 2021, Accepted: $1^{\text {st }}$ May 2021.

Gupta S, Saxena U, Arora R, Zutshi V, Aggarwal R. Comparative analysis of fetomaternal outcome in women with gestational diabetes mellitus managed on different modalities. The New Indian Journal of OBGYN. 2022; 8(2): $246-50$. 
in obese women, without any effect on the development of GDM or neonatal birth weight. ${ }^{9}$

A prospective clinical trial that randomised women with GDM to insulin or metformin found that, metformin therapy was not associated with an increased risk of perinatal complications. ${ }^{10}$ Previous meta-analyses have also found that there is no difference in perinatal outcomes, for women with GDM, treated with metformin versus insulin. ${ }^{11,12}$ Some women managed first with metformin, may require additional therapy with insulin to achieve euglycemia, but the dose of insulin needed along with it is much less than, when managed with standalone insulin therapy. ${ }^{13}$

A recent study concluded that metformin treatment in the first trimester of pre-gestational diabetes was associated with an increased risk of birth defects and pregnancy loss but these increased risks were attributed to hyperglycaemia rather than metformin therapy. ${ }^{14}$ Needle phobia, life threatening hypoglycemia, weight gain, daily injections, and psycho-social stigma, makes injectable therapy with insulin unwelcomed in pregnant women with GDM. ${ }^{15}$

At our institution, the use of metformin for the treatment of GDM has been adopted as an alternative approach to insulin therapy. Thus, the aim of the present study was to carry out an audit to assess and compare the maternal characteristics and perinatal outcomes of women with GDM treated with metformin (with or without supplemental insulin), in comparison to those treated solely with insulin or MNT and lifestyle modification alone in tertiary care hospital settings.

\section{Materials and methods}

This study was conducted at department of obstetrics and gynaecology, Vardhman Mahavir Medical College and Safdarjung Hospital, New Delhi. In this retrospective observational study, fetomaternal outcome of all women with singleton pregnancy diagnosed with GDM, managed on different modality of treatment, was analyzed from inpatient clinical records from January 2018 to June 2019, over a period of 18 months. Women with GDM with multiple pregnancy, chronic hypertension, overt diabetes, bad obstetric history and PCOS patients on metformin, were excluded from the study.

All study women were divided into groups based on modality of treatment on which their fasting blood sugar was $<95 \mathrm{mg} / \mathrm{dl}$ and postprandial 2 hours blood sugar $<120 \mathrm{mg} / \mathrm{dl}$. The four study groups were as follows: Group A - MNT, Group B - MNT plus metformin, Group C - MNT plus insulin and Group D - MNT plus metformin plus insulin.
Diagnosis of GDM was made on guidelines of diabetes in pregnancy study group of India (DIPSI). DIPSI is done as a single step procedure irrespective of the last meal. Pregnant women attending the antenatal OPD were given $75 \mathrm{~g}$ anhydrous glucose in $250-300 \mathrm{ml}$ of water and plasma glucose was estimated after 2 hour. A 2 hours plasma glucose $\geq 140 \mathrm{mg} / \mathrm{dl}$ was taken as GDM and a value of $\geq 200$ $\mathrm{mg} / \mathrm{dl}$ as DM. If the DIPSI value at first visit was normal then test was further repeated at 24-28 weeks and at 32-34 weeks in high risk women.

GDM women managed on different modality of treatment were considered to have controlled blood sugar when fasting sugar was less than or equal to $95 \mathrm{mg} / \mathrm{dl}$ and post prandial blood sugar, 2 hours after meals less than or equal to $120 \mathrm{mg} / \mathrm{dl}$. Case records were studied to record various fetomaternal outcomes. Maternal outcome studied, in all the study groups, were mode of delivery, period of gestation, occurrence of polyhydramnios, urinary tract infection (UTI), hypertensive disease in pregnancy and postpartum haemorrhage (PPH). Neonatal outcome studied were birth weight, gestational age at birth, macrosomia, fetal growth restriction (FGR), shoulder dystocia, NICU admission, jaundice, birth injury, neonatal death, still birth and Apgar score at birth.

Statistical analysis: Statistical package for social sciences (SPSS) software version 23.0 was used for analysis. The data was entered in Microsoft excel spreadsheet. Categorical variables presented in number and percentage and continuous in mean $\pm \mathrm{SD}$ and median. Normality of data was tested by Shapiro- wilk test. Comparison of variable, quantitative and qualitative using paired/ unpaired t-test and chi square test respectively and $\mathrm{P}$ value of $<0.05$ was considered statistically significant.

\section{Results}

In this retrospective study on women with GDM in singleton pregnancy, a total of 352 women were included as per inclusion criteria. Out of these, 90 patients $(25.57 \%)$ each were in metformin only and insulin only group, thirty two $(9 \%)$ were managed with metformin plus insulin and majority, 140 women (39.77\%) were managed with MNT.

The metformin dose varied from $500 \mathrm{mg}$ to $2 \mathrm{gm}$ a day with a mean dose of $1 \mathrm{gm}$ a day. In the insulin treated group $(\mathrm{n}=90), 27$ patients were treated with short acting insulin only, 19 patients were treated with intermediate acting insulin only, and 44 patients were treated with both short and intermediate acting insulin.

All the 4 groups of the women in this study were matched for various variables. Glucose values in OGTT at 
$2 \mathrm{hrs}$ were significantly higher $(\mathrm{p}<0.0001)$ in the insulin group than in metformin group which when compared with the MNT were also significantly higher $(\mathrm{p}<0.0001)$ in metformin group.

There were no statistically significant difference between the metformin and insulin only group with respect to admission $(p=0.755)$. Similarly occurrence of jaundice $(\mathrm{p}=0.798)$, stillbirth $(\mathrm{p}=0.650)$ and Apgar score at 5 mins $(p=0.0914)$ were also not significant between the metformin group and insulin group. No incidence of birth injury and neonatal death were documented in both the groups (table 2).

There were no statistically significant difference between

Table 1: Showing maternal parameters

\begin{tabular}{|c|c|c|c|c|c|c|c|}
\hline \multicolumn{2}{|l|}{ Parameters } & $\begin{array}{l}\text { Metformin } \\
(\mathrm{n}=90)\end{array}$ & $\begin{array}{l}\text { Insulin } \\
(\mathbf{n}=90)\end{array}$ & $\begin{array}{l}\text { MNT } \\
(n=140)\end{array}$ & $\begin{array}{l}\text { Metformin }+ \\
\text { insulin }(n=32)\end{array}$ & $\begin{array}{l}\text { Met.vs. Ins. } \\
\text { (p value) }\end{array}$ & $\begin{array}{l}\text { Met. vs. MNT } \\
\text { (p value ) }\end{array}$ \\
\hline \multicolumn{2}{|l|}{ Age (yrs) } & $26.2 \pm 4.6$ & $26.8 \pm 4.2$ & $26.3 \pm 4.0$ & $27.6 \pm 4.1$ & NS $(0.3621)$ & NS (0.8617) \\
\hline \multicolumn{2}{|c|}{ Total weight gain $(\mathrm{kg})$} & $10.8 \pm 4.6$ & $11.2 \pm 5.6$ & $10.6 \pm 4.1$ & $11.8 \pm 4.1$ & NS (0.6012) & NS $(0.7311)$ \\
\hline \multicolumn{2}{|c|}{ OGTT $(2 \mathrm{hrs})(\mathrm{mmol} / \mathrm{l})$} & $8.8 \pm 1.2$ & $10.4 \pm 1.8$ & $7.8 \pm 0.8$ & $10.9 \pm 1.0$ & $\mathrm{SS}(<0.0001)$ & $\mathrm{SS}(<0.0001)$ \\
\hline \multicolumn{2}{|c|}{ Gestational age (OGTT) } & $22.3 \pm 1.2$ week & $22.1 \pm 1.1$ week & $22.2 \pm 1.4$ week & $22.1 \pm 2.0$ week & $\mathrm{NS}(0.2454)$ & NS $(0.5771)$ \\
\hline Mode & Caesarean section & 28 & 21 & 30 & 10 & & \\
\hline of & Assisted vaginal & 6 & 7 & 10 & 4 & NS $(0.420)$ & NS (0.254) \\
\hline delivery & Vaginal & 56 & 62 & 100 & 18 & & \\
\hline Polyhydramnios & & 30 & 24 & 28 & 13 & NS (0.329) & NS $(0.0230)$ \\
\hline UTI & & 5 & 8 & 5 & 4 & NS (0.387) & $\mathrm{NS}(0.471)$ \\
\hline Hypertension & & 6 & 7 & 5 & 13 & NS (0.773) & NS (0.283) \\
\hline $\mathrm{PPH}$ & & 5 & 9 & 4 & 1 & NS $(0.2656)$ & NS $(0.303)$ \\
\hline
\end{tabular}

MNT - Medical nutritional therapy, OGTT - Oral glucose tolerance test, UTI - Urinary tract infection, PPH - Postpartum haemorrhage, NS Nonsignificant.

maternal age $(\mathrm{p}=0.3621)$, total weight gain during pregnancy $(\mathrm{p}=0.6012)$, mode of delivery (normal, assisted, caesarean) $(\mathrm{p}=0.420)$, prematurity $\quad(\mathrm{p}=0.059)$ UTI $\quad(\mathrm{p}=0.387)$, the metformin group when compared to MNT only group in relation to birth weight $(\mathrm{p}=0.0975)$, gestational age $(\mathrm{p}=$ hypertension $(\mathrm{p}=0.773)$, PPH $(\mathrm{p}=0.2656)$, and polyhydramnios $(\mathrm{p}=0.329)($ table 1$)$.

There were also no statistically significant difference between the metformin and medical nutritional therapy with $0.2194)$, occurrence of macrosomia ( $\mathrm{p}=0.847)$, FGR ( $\mathrm{p}=$ $0.835)$, shoulder dystocia $(\mathrm{p}=0.653)$ and NICU admission $(p=0.659)$. Similarly occurrence of jaundice $(p=0.933)$, stillbirth $(\mathrm{p}=0.325)$ and Apgar score at $5 \mathrm{~min}(\mathrm{p}=1.000)$ were also not statistically significant between the metformin

Table 2: Showing neonatal parameter

\begin{tabular}{|c|c|c|c|c|c|c|}
\hline Parameters & $\begin{array}{l}\text { Metformin } \\
(\mathrm{n}=90)\end{array}$ & $\begin{array}{l}\text { Insulin } \\
(\mathrm{n}=90)\end{array}$ & $\begin{array}{l}\text { MNT } \\
(n=140)\end{array}$ & $\begin{array}{l}\text { Met+ Ins } \\
(\mathrm{n}=32)\end{array}$ & $\begin{array}{l}\text { Met. vs. Ins. } \\
\text { (p value) }\end{array}$ & $\begin{array}{l}\text { Met.vs. MNT } \\
\text { (p value) }\end{array}$ \\
\hline Birth weight (gms) & $2880 \pm 210$ & $2900 \pm 180$ & $2830 \pm 230$ & $3160 \pm 110$ & NS (0.4936) & NS $(0.0975)$ \\
\hline Gestational age (weeks) & $38.1 \pm 1.2$ & $37.8 \pm 1.9$ & $38.4 \pm 2-1$ & $37.0 \pm 0.8$ & NS $(0.207)$ & NS $(0.2194)$ \\
\hline FGR & 1 & 1 & 2 & 1 & NS (1.000) & NS $(0.835)$ \\
\hline Shoulder dystocia & 2 & 1 & 2 & 1 & NS $(0.560)$ & NS (0.653) \\
\hline NICU admission & 5 & 6 & 6 & 4 & NS $(0.755)$ & NS (0.659) \\
\hline Jaundice & 8 & 9 & 12 & 3 & NS (0.798) & NS $(0.933)$ \\
\hline Neonatal death & 0 & 0 & 0 & 0 & NS & NS \\
\hline Still birth & 2 & 3 & 1 & 2 & NS $(0.650)$ & NS $(0.325)$ \\
\hline Apgar score at 5 mins & $8.9 \pm 1$ & $8.7 \pm 0.5$ & $8.9 \pm 0.5$ & $8.4 \pm 0.4$ & NS ( 0.0914$)$ & NS (1.000) \\
\hline
\end{tabular}

FGR - Fetal growth restriction, NICU - Neonatal intensive care unit, NS - Nonsignificant

respect to maternal age $(\mathrm{p}=0.8617)$, total weight gain during pregnancy $(\mathrm{p}=0.7311)$, mode of delivery (normal, assisted, caesarean) $(\mathrm{p}=0.254), \quad$ prematurity $(\mathrm{p}=0.125), \operatorname{UTI}(\mathrm{p}=$ $0.471)$, hypertension ( $\mathrm{p}=0.283)$, and PPH $\quad(\mathrm{p}=0.303)$, but polyhydramnios was significantly higher $(\mathrm{p}=0.0230)$ in metformin group than in MNT group.

There were no statistically significant difference between the metformin group when compared to insulin only, in relation to birth weight $(\mathrm{p}=0.4936)$, gestational age $(\mathrm{p}=$ $0.207)$, occurrence of macrosomia $(\mathrm{p}=0.732)$, FGR $(\mathrm{p}=$ $1.000)$, shoulder dystocia $(\mathrm{p}=0.560)$ and need for NICU group and MNT only group. No incidence of birth injury and neonatal death were documented in both the groups.

\section{Discussion}

Metformin use in GDM has not gained widespread acceptance because the evidence of safety and efficacy has largely been derived from inadequately powered study.

Data from our study was similar to study done by Kristiina et $\mathrm{al}^{16}$, as there were no statistically significant difference in maternal weight gain during pregnancy, gestational week at the time of performing OGTT, mode of delivery, prematurity, postpartum haemorrhage (PPH) 
between the metformin group and insulin only group. Glucose levels in OGTT at $2 \mathrm{hrs}$ in our study were consistent with the study by Kristina et $\mathrm{al}^{16}$, as in both the study there was significant difference between blood sugar level, in women who were controlled on metformin versus insulin.

In contrary to our study, the maternal weight gain during pregnancy was less in metformin group than insulin group, both groups were comparable according to obstetrics and neonatal complications in the study done by Shirin $\mathrm{N}$ et $\mathrm{al}^{17}$. The occurrence of gestational hypertension, in our study, was also not statistically significant between metformin and insulin group, and same had been also observed by Balani et $\mathrm{al}^{18}$. Incidence of UTI and polyhydramnios was also not statistically significant between maternal data from metformin versus insulin only group of women and metformin versus and MNT group. But incidence of polyhydramnios was significantly higher in metformin group in comparison to MNT group.

A small randomized pilot study of 30 patients with GDM found that neonatal outcomes were not different between patients treated with metformin and those on standard insulin therapy. ${ }^{19}$ Similarly, analysis of neonatal data in our study showed no statistical significance when compared between metformin and insulin only group of the patients in relation to birth weight, Apgar score at $5 \mathrm{~min}$, macrosomia, FGR, NICU admission, and jaundice. These analytical findings also were similar to the study by Kristina et $\mathrm{al}^{16}$. Incidence of shoulder dystocia was also not clinical significant when compared to metformin versus insulin only as well as metformin versus MNT and similar was reported by Balani et $\mathrm{al}^{18}$. No serious adverse effect of metformin was reported in our study.

The limitation of this study is that it is a retrospective study hence randomization was not possible. Its possible that insulin treated patients were having more hyperglycemia than metformin treated patients as evident by OGTT at $2 \mathrm{hrs}$. Similarly the metformin treated patients were more hyperglycemic in comparison to MNT only group of the patients as shown by OGTT values at $2 \mathrm{hrs}$.

\section{Conclusion}

In the present study, metformin was observed to be an effective oral hypoglycemic drug in the treatment of gestational diabetes mellitus (GDM). Metformin was not found to be associated with increased maternal and neonatal complications in comparison to insulin. Before making any final recommendation for GDM management, further sufficiently powered prospective randomized study of larger number of women is required, including long term follow up of their children, so that we determine the role of metformin as an effective alternative treatment to insulin in their management.

\section{Conflict of interest: None. Disclaimer: Nil.}

\section{References}

1. American Diabetes Association. Standards of medical care in diabetes - 2014. Diabetes Care. 2014; 37 (Suppl 1): S14-80.

2. Moses RG, Wong VC, Lambert K, Morris GJ, San Gil F. The prevalence of Hyperglycaemia in pregnancy in Australia. Aust. N. Z. J. Obstet. Gynaecol. 2016; 56: 341- 45.

3. Crowther CA, Hiller JE, Moss JR, McPhee AJ, Jeffries WS, Robinson JS, et al. Effect of treatment of gestational diabetes mellitus on pregnancy outcomes. $\mathrm{N}$ Engl J Med. 2005; 352: 2477-86.

4. Metzger BE, Buchanan TA, Coustan DR, et al. Summary and recommendations of the Fifth International Workshop- Conference on Gestational Diabetes Mellitus. Diabetes Care. 2007; 30 (S2): S251S260.

5. Kwik M, Seeho SK, Smith C, McElduff A, Morris JM. Outcomes of pregnancies affected by impaired glucose tolerance. Diabetes Res Clin Pract. 2007; 77: 263-68.

6. Kitwitee P, Limwattananon S, Limwattananon C, et al. Metformin for the treatment of gestational diabetes: An updated meta-analysis. Diabetes Res. Clin Pract. 2015; 109: 521 - 32 .

7. Dhulkotia JS, Ola B, Fraser R, Farrell T. Oral hypoglycemic agents vs insulin in management of gestational diabetes: A systematic review and metaanalysis. Am J Obstet Gynecol. 2010; 203: 457.e1457.e9.

8. Niromanesh S, Alavi A, Sharbaf F.R, Amjadi N, Moosavi S, Akbari S. Metformin compared with insulin in the management of gestational diabetes mellitus: A randomized clinical trial. Diabetes Res Clin Pract. 2012; 98: 422 - 29.

9. Syngelaki A, Nicolaides KH, Balani J, et al. Metformin versus Placebo in Obese Pregnant Women without Diabetes Mellitus. N Engl J Med. 2016; 374: 434 - 43.

10. Rowan JA, Hague WM, Gao W, Battin MR, Moore MP. Metformin versus insulin for the treatment of gestational diabetes. N Engl J Med. 2008; 358: 2003 - 15.

11. Balsells M, Garcia-Patterson A, Sola I, et al. Glibenclamide, metformin, and insulin for the treatment 
The New Indian Journal of OBGYN. 2021 (January-June);8(2)

of gestational diabetes: A systematic review and metaanalysis. BMJ. 2015; 350: h102.

12. Zhao LP, Sheng XY, Zhou S, Yang T, et al. Metformin versus insulin for gestational diabetes mellitus: A metaanalysis. Br J Clin Pharmacol. 2015; 80: 1224 - 34.

13. Donovan PJ, McIntyre HD. Drugs for gestational diabetes. Aust Prescr. 2010; 33: 141- 44.

14. Panchaud A, Rousson V, Vial T, Bernard N, et al. Pregnancy outcomes in women on metformin for diabetes or other indications among those seeking teratology information services. Br J Clin Pharmacol. 2018; 84: 568 - 78.

15. Moore LE, Briery CM, Clokey D, Martin RW, Williford NJ, Bofill JA, et al. Metformin and insulin in the management of gestational diabetes mellitus: Preliminary results of a comparison. J Reprod Med. 2007; 52: $1011-5$.

16. Tertti K, Ekblad U, Koskinen P, Vahlberg T, Rönnemaa T. Metformin vs. insulin in gestational diabetes. A randomized study characterizing metformin patients needing additional insulin. Diabetes Obes Metab. 2013 Mar;15(3): 246-51.
17. Niromanesh S, Alavi A, Rahimi Sharbaf F, Amjadi N, Moosavi S, Akbari S. Metformin compared with insulin in the management of gestational diabetes mellitus: A randomized clinical trial. Diabetes Research and Clinical Practice. 2012; 98: 422-26.

18. Balani J, Hyer SL, Rodin DA, Shehata H. Pregnancy outcomes in women with gestational diabetes treated with metformin or insulin: a case-control study. Diabet Med. 2009; 26: 798 - 802.

19. Coetzee EJ, Jackson WP. Metformin in management of pregnant insulin-independent diabetics. Diabetologia. 1979; 16: 241-5.

\footnotetext{
Sumedha Gupta ${ }^{1}$, Upma Saxena ${ }^{2}$, Renu Arora ${ }^{3}$, Vijay Zutshi $^{4}$, Ritu Aggarwal ${ }^{5}$

${ }^{1}$ Senior Resident, Dept of OBGYN, VMMC\& Safdarjung Hospital, New Delhi, India; ${ }^{2}$ Professor, Dept of OBGYN, VMMC \& Safdarjung Hospital, New Delhi, India;

${ }^{3}$ Professor, Dept of OBGYN, VMMC \& Safdarjung Hospital, New Delhi, India; ${ }^{4}$ Professor, Dept of OBGYN, VMMC\& Safdarjung Hospital, New Delhi, India; ${ }^{5} \mathrm{CMO}$, Dept of OBGYN, VMMC\& Safdarjung Hospital, New Delhi, India.
} 